\title{
473178 - POTASSIUM CONCENTRATION OF BLOOD TRANSFUSED IN THE OPERATING ROOM
}

Wei-Shuen Tan, $\mathrm{MD}^{1}$, Brian Muirhead, $\mathrm{MD}^{2}$

1. Department of Anesthesia, University of Manitoba, Winnipeg, MB, Canada

2. Department of Anesthesia, Health Sciences Centre, Winnipeg, MB, Canada

Introduction: The potassium load of a unit of red blood cells (RBCs) is estimated at 5.5 mEq per unit after 35 days of storage (1). In the operating room, RBCs are often infused centrally, through a fluid warmer, and under pressure. The actual infused postassium concentration of RBCs in this setting was determined.

Methods: Local REB approval was obtained for this study. Twenty-five randomly selected units of blood transfused in the operating room were studied. All units were undiluted and given through a filter and fluid warmer. The age of the blood and use of a pressure bag were recorded. A sample was taken from the intravenous line, distal to the fluid warmer, and analyzed for potassium concentration by blood gas analysis.

Results: Potassium concentration of transfused blood varied considerably and was related to the age of the blood. The use of a pressure bag does not convincingly increase the potassium load of banked blood.

Discussion: Transfusion of RBCs in the operating room may be associated with a large, rapidly infused potassium load, particularly as the age of the RBCs increases. For patients who require rapid transfusion and are at risk for hyperkalemia, washing of RBCs prior to transfusion can minimize the risk of acute hyperkalemia and the associated complications (2).

References: (1) Transfusion 1981 21: 135-7 (2) Transfusion 2007 47: 248-50

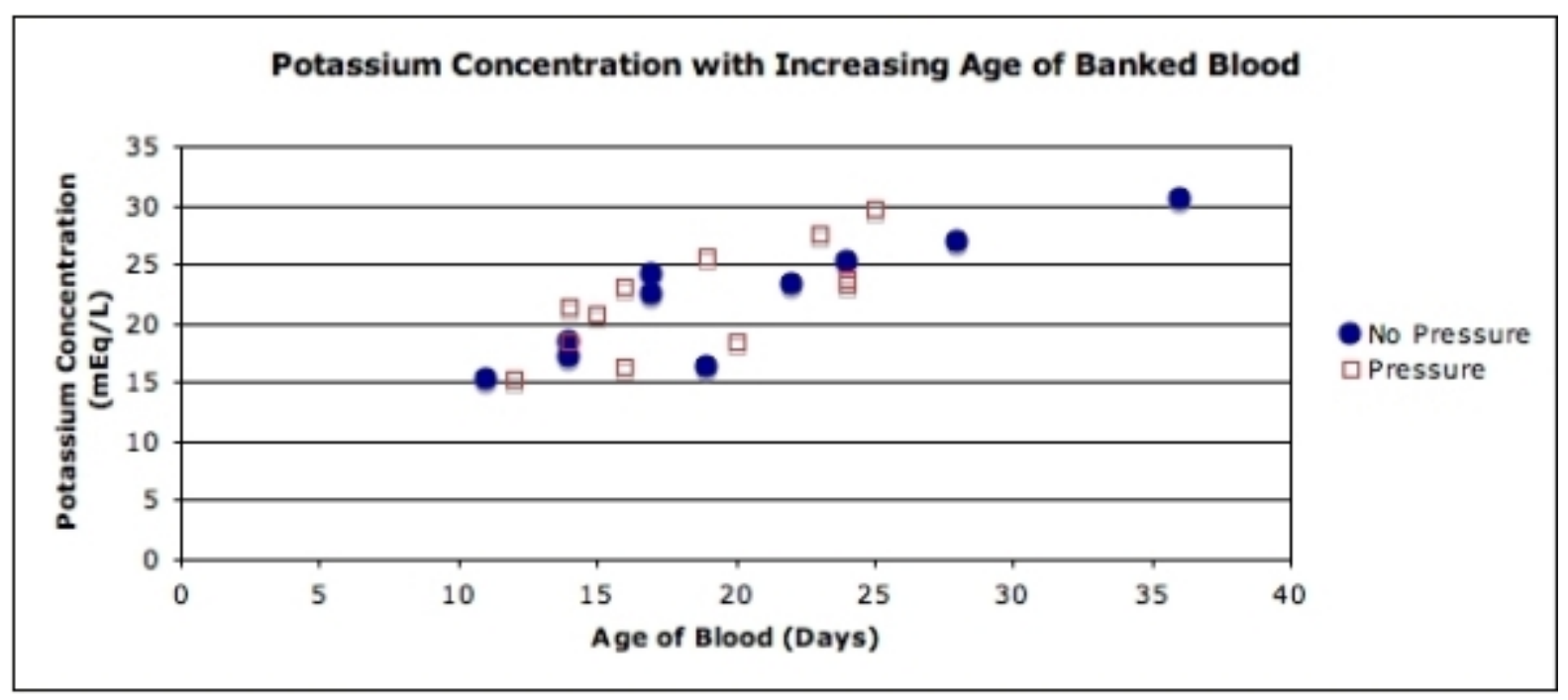

